\title{
THE FIGHT AGAINST TRACHOMA IN THE ISLAND OF MALTA**
}

\author{
BY \\ F. J. DAMATO \\ Malta, G.C.
}

TRAChoma was the most widespread and serious eye disease in Malta 50 years ago, and though it is still the cause of 12 per cent. of all cases of blindness, these are all long-standing cases, and to-day a new case is a rarity.

It is the purpose of this paper to discuss the measures adopted and the changes in surroundings and living standards which have led to the almost complete elimination of trachoma.

Before and after the first world war, the poor economic and social conditions of the middle and lower classes in Malta contributed to the very high incidence of trachoma. The standard of housing in most towns and villages was low. The houses were small and lacked proper sanitation and an indoor water supply, families were large, and many children had to sleep together in one room in close contact. As it was often necessary to draw water from public taps and carry it home, it is easy to understand that water was drawn very infrequently, laundering was irregular, and the danger of several persons using the same towels and washing in the same water could hardly be avoided. Flies and vermin bred freely. The diet of the low classes was poor, consisting largely of carbohydrates, with very little fats or meat.

Individual efforts to eradicate the disease were not lacking, but the first general move against trachoma was made in 1911, when a set of instructions was circulated to the Government elementary schools, to prevent the spread of communicable diseases including trachomatous conjunctivitis. It was ruled that no child, teacher, or caretaker should attend school while suffering from trachoma, until medically certified as cured. Notes were also published to assist teachers in the detection of suspected cases of trachoma. These measures helped to draw the attention of parents to the danger of the disease and to stop its spread among children at school. In 1919, special measures were enacted and dispensaries where patients could receive free daily treatment were established in all towns and villages. The majority of cases were sent to the Eye Clinic at the Central Hospital.

In 1922 trachoma was made a notifiable disease, and during this year 1,282 cases were notified, though this figure represented a small fraction of the real

\footnotetext{
* Received for publication March 28, 1960.
} 
incidence. A considerable number of patients were not bad enough to ask for treatment and others were reluctant to attend the Eye Clinic.

As it was well known that the disease usually starts very early in life, usually in the 5-to 15-year age group or earlier, the main line of attack was the detection, segregation, and treatment of the infected child. When in 1924 education was made compulsory until the age of 14 for children already at school, an opportunity was provided to discover and treat the trachomatous child. A team of school medical officers and an ophthalmic specialist started regular examinations of the eyes of children in all classes. In order to ensure continuity of treatment during the summer holidays, money prizes were given to children who reported regularly for treatment. A ward for trachomatous children, who for some reason could not attend the outpatients' clinic, was opened in one of the hospitals. A certificate of freedom from trachoma was required before a child was accepted in a school, orphanage, or any other institution. Children were taught to avoid touching their eyes with their fingers and to wash the eyelids with soap and water at least once a day.

The treatment in use at that time included the local application of caustics, mechanical rolling of the tarsal conjunctiva, and dealing with complications. This, though valuable, served obviously to hasten the process of cicatrization which was considered a cure.

In the last few years before the second world war, economic and social conditions of the island were much improved. More and better houses were being built, sanitation and a piped water-supply were extended to most of the towns and villages, overcrowding was diminishing, the number of schools was increased, and the purchasing power of the lower classes was raised as was shown by the increased consumption of fats and meat. Most important of all was the control of the fly by means of health education and propaganda, improved sanitation, and the use of chemical insecticides. The sight of a miserable child with the face and eyelids covered with flies became a thing of the past.

In the years since the second world war, the incidence of trachoma has been very low. The standard of living has continued to rise and compulsory education for all children over 6 years of age was introduced in 1946. All these measures to control and fight the spread of trachoma gradually started to give results. Table I shows the new cases of trachoma notified during the period 1929 to 1939. Except for the year 1935,

TABLE I

CASES OF TRACHOMA NOTIFIED, 1929 TO 1938

\begin{tabular}{c|c|c}
\hline Year & $\begin{array}{c}\text { No. of } \\
\text { New Cases } \\
\text { Notified }\end{array}$ & $\begin{array}{c}\text { No. of Old } \\
\text { Cases under } \\
\text { Treatment }\end{array}$ \\
\hline 1929 & 1,142 & - \\
1930 & 984 & - \\
1931 & 617 & - \\
1932 & 553 & - \\
1933 & 329 & $\overline{1}$ \\
1934 & 290 & 1,715 \\
1935 & 509 & 1,073 \\
1936 & 237 & 1,039 \\
1937 & 240 & 960 \\
1938 & 231 & \\
\hline
\end{tabular}


there is a sustained decrease. Table II shows the number of cases of trachoma treated at the Eye Clinic at the Central Hospital, and the number of trachoma cases admitted because of complications and major eyelid operations during the period 1925 to 1958 . In $1925,56.5$ per cent. of the eye patients examined at the Central Hospital were suffering from trachoma. In 1958 there were only 27 new cases, 0.5 per cent. of all eye cases examined during the year. It is to be noted that there has been no similar decrease in the incidence of trachoma in the other Mediterranean countries, such as North Africa, where the standards of living and sanitation have remained very low.

TABLE II

DECLINE IN INCIDENCE OF TRACHOMA AND ITS COMPLICATIONS, 1925-1958

\begin{tabular}{|c|c|c|c|c|c|}
\hline \multirow{2}{*}{ Year } & \multirow{2}{*}{$\begin{array}{l}\text { Total } \\
\text { No. of Out- } \\
\text { Patients }\end{array}$} & \multicolumn{2}{|c|}{ Trachoma Cases } & \multirow{2}{*}{$\begin{array}{c}\text { Trachoma } \\
\text { Cases with } \\
\text { Complications }\end{array}$} & \multirow{2}{*}{$\begin{array}{c}\text { Trachoma } \\
\text { Cases } \\
\text { Requiring } \\
\text { Major Lid } \\
\text { Operations }\end{array}$} \\
\hline & & No. & Percentage & & \\
\hline $\begin{array}{l}1925 \\
1930 \\
1936 \\
1939 \\
1943 \\
1948 \\
1951 \\
1952 \\
1953 \\
1954 \\
1955 \\
1956 \\
1957 \\
1958\end{array}$ & $\begin{array}{l}1,063 \\
2,226 \\
2,036 \\
2,047 \\
1,079 \\
2,627 \\
3,800 \\
3,624 \\
2,699 \\
4,765 \\
4,824 \\
4,070 \\
4,825 \\
4,796\end{array}$ & $\begin{array}{r}572 \\
895 \\
673 \\
685 \\
250 \\
299 \\
126 \\
42 \\
53 \\
90 \\
56 \\
22 \\
28 \\
27\end{array}$ & $\begin{array}{r}56.5 \\
40.7 \\
33.2 \\
33.4 \\
23.0 \\
11.0 \\
3.3 \\
1.4 \\
1.9 \\
1.9 \\
1.1 \\
0.5 \\
0.5 \\
0.5\end{array}$ & $\begin{array}{r}176 \\
184 \\
101 \\
60 \\
10 \\
26 \\
- \\
- \\
- \\
- \\
-\end{array}$ & $\begin{array}{r}100 \\
61 \\
30 \\
18 \\
5 \\
18 \\
4 \\
10 \\
6 \\
4 \\
11 \\
3 \\
3 \\
1\end{array}$ \\
\hline
\end{tabular}

As in other parts of the world, the introduction of the sulphonamides brought a considerable change in the treatment of trachoma. Under the form of Prontosil album and rubrum, the sulphonamides were first used in Malta in 1936. The knowledge that trachoma could be treated orally encouraged the attendance of those patients who had been reluctant to attend the Eye Clinic because of the discomforts accompanying the old treatment.

All the patients seen during 1951-1958 were discovered during the routine examination of school children and immigrants; all were asymptomatic and most of them were in the 5- to 15-year age group. An isolated case in a large family was just as common as infection in all the members of the family. In the majority the trachoma was at Stage IIa, showing the typical follicles, most numerous in the upper retrotarsal fold. All the patients came from the lower classes living in overcrowded surroundings, and there is no doubt that further improvement in these unhealthy conditions will eventually lead to the complete elimination of the few surviving pockets of resistance. 
The response to sulphonamide and antibiotic therapy has been very satisfactory, a cure being obtained after a treatment lasting between 2 and 4 months, though some took as long as 6 months. The follicles gradually disappeared and the conjunctiva became smooth, with no apparent scar formation. Table III shows the number of cases treated by various methods.

TABLE III

TRACHOMA CASES TREATED BY SULPHONAMIDES AND ANTIBIOTICS, 1951-58

\begin{tabular}{|c|c|c|c|c|}
\hline \multirow[b]{2}{*}{ Year } & \multicolumn{3}{|c|}{ Therapy } & \multirow{2}{*}{$\begin{array}{l}\text { Total No } \\
\text { of Cases } \\
\text { Treated }\end{array}$} \\
\hline & $\begin{array}{l}\text { Sulphonamides } \\
\text { Only }\end{array}$ & $\begin{array}{c}\text { Sulphonamides } \\
+ \\
\text { Antibiotics }\end{array}$ & $\begin{array}{l}\text { Antibiotics } \\
\text { Only }\end{array}$ & \\
\hline $\begin{array}{l}1951 \\
1952 \\
1953 \\
1954 \\
1955 \\
1956 \\
1957 \\
1958\end{array}$ & $\begin{array}{r}74 \\
35 \\
45 \\
4 \\
6 \\
2 \\
-\end{array}$ & $\begin{array}{r}41 \\
7 \\
8 \\
24 \\
2 \\
9 \\
-\end{array}$ & $\begin{array}{r}11 \\
\overline{7} \\
66 \\
50 \\
7 \\
26 \\
27\end{array}$ & $\begin{array}{r}126 \\
42 \\
53 \\
90 \\
56 \\
22 \\
28 \\
27\end{array}$ \\
\hline Total & 166 & 91 & 187 & 444 \\
\hline
\end{tabular}

Sulphonamides were administered in the following ways:

(1) Tablets 0.5 g. 4-hrly for 10 days.

(2) Instillation every hour during the day of sulphonamide solution 10 per cent.

(3) Sulphonamide ointment at night.

187 cases were treated with antibiotics. Oily suspensions of aureomycin and achromycin 1 per cent. with hydrocortisone 0.5 per cent. were instilled every hour during the day, and achromycin or aureomycin ointment was used at night. Terramycin and tetracycline drops and ointments were also used.

In assessing the main factors leading to the elimination of trachoma from the Island of Malta, one cannot help remarking that, though the detection and treatment of the infected patients played an important role, no decisive results could have been obtained without an improvement in living standards, universal education, the creation of hygienic surroundings, and the elimination of dirt and poverty.

\section{REFERENCE}

GURD, D. P. (1943). J. roy. nav. med. Serv., 29, 171, 237. 